\title{
Dynamics of dual film formation in boundary lubrication of steels \\ Part II. Chemical analyses
}

\author{
Bülent Çavdar and Kenneth C. Ludema* \\ Mechanical Engineering Department, University of Michigan, Ann Arbor, MI 48109-2125 (U.S.A.)
}

(Received October 3, 1990; revised January 21, 1991; accepted February 13, 1991)

\begin{abstract}
Effective "breaking-in" of lubricated steel surfaces has been found to be due primarily to the rate of growth of "protective" films of oxides and compounds derived from the lubricant. The protection afforded by the films is strongly dependent on lubricant chemistry, steel composition, original surface roughness and the load/speed sequence or history in the early stages of sliding. Given the great number of variables involved it is not possible to follow more than a few of the chemical changes on surfaces using the electron, ion and X-ray column analytical instruments at the end of experiments. Ellipsometry was therefore used to monitor the formation and loss of dual protective films in real time, and detailed chemical analysis was done at various stages to calibrate the ellipsometer. This work is reported in three interlinking parts: I, Functional Nature and Mechanical Properties; II, Chemical Analyses; III, Real-time Monitoring with Ellipsometry.
\end{abstract}

\section{Introduction}

The chemical changes on the surfaces of boundary lubricated steels have been discussed for over 30 years. A review of the literature does not provide a clear or consistent picture of the chemical changes occurring on sliding surfaces. The most widely discussed views on this subject are summarized in the following paragraphs.

Fein and Kreuz [1] used 52100 steel, aromatic and saturated hydrocarbons in a four-ball machine with a sliding speed of $0.0035 \mathrm{~m} \mathrm{~s}^{-1}$. They claimed that both low and high ratios of oxygen to hydrocarbon in the oil favor high wear and ferric oxide $\left(\mathrm{Fe}_{2} \mathrm{O}_{3}\right.$ and $\left.\mathrm{Fe}_{3} \mathrm{O}_{4}\right)$ wear products. Certain intermediate ratios favor low wear and the formation of an oxygenated organic "friction polymer" which prevented metallic contact. Fein and Kreuz [2] stated that chemical changes in the lubricant, occurring in the zone of contact, produce polymeric materials of high viscosity which can cushion asperity interaction hydrodynamically. They assumed that aromatic hydrocarbons dissolve much more oxygen than do saturated hydrocarbons. However, some tabulated data show that oxygen solubility is about the same in both oils [3]. Therefore, the difference in wear behavior must be due to some more important variable which Fein and Kreuz did not discuss. These might include surface hardness and microstructure of their steel specimens and the break-in procedure (such as stop-start frequency, variation in loading etc., at the very beginning of sliding).

*Author to whom correspondence should be addressed. 
Bose ef al. [4] evaluated the wear products from a four-ball machine using refined mineral oil. The organic portion of the insoluble wear debris ranged from $77 \%$ to $85 \%$ of the total in dry air, nitrogen and argon. The high percentage of organic constituents was typical for scuffing wear in the four-ball tester. They agreed that dissolved oxygen in mineral oil was an effective wear reducing additive. However, they added that dissolved oxygen might have acted as a catalyst for the formation of organometallic wear debris.

Bjerk [5] has shown by microprobe analysis that the protective layer developed on a steel roller lubricated by plain mineral oil is rich in oxygen. Kang and Ludema [6] analyzed the flim compositions formed on steel surfaces after sliding in water and in plain paraffin oil. They used Auger electron spectroscopy and found that the films formed in water were rich in $\mathrm{Fe}_{2} \mathrm{O}_{3}$ while those in paraffin oil were rich in fakeshaped $\mathrm{Fe}_{3} \mathrm{O}_{4} \cdot \mathrm{Fe}_{2} \mathrm{O}_{3}$ films were abrasive and did not protect the surfaces well from wear. In contrast, $\mathrm{Fe}_{3} \mathrm{O}_{4}$ flims were ductile and protected the sliding surfaces very well.

Boundary films formed in lubricants containing a small amount of ZDP (zine dialkyldithiophosphate) carry higher loads than do films formed in plain lubricants. Many researchers have used electron spectroscopy for chemical analysis (ESCA) (or $X$-ray photoelectron spectroscopy (XPS) to determine the composition of these films [3-5]. Baldwin [7] proposed the formation of $\mathrm{FeO}$ and metal sulfides. Bird and Galvin [8] proposed that polymeric films containing zinc, phosphorus and sulfur are formed. They ruled out the presence of zinc phosphide, zinc phosphate, zinc sulfate, zinc sulfide or iron phosphate in the films. In contrast, Watkins [9] proposed that zinc polyphosphates and iron sulfide do form. Martin et al. [10] have shown by EXAFS analysis that iron, oxygen, sulfur, phosphorus and zinc are bound to each other in an amorphous structure. They were not able to detect carbon and hydrogen with the techniques they used.

Overall, it appears that much of the chemical research effort in boundary lubrication has been devoted to detection of the sulfur and phosphorus compounds and yet there is neither quantitative information nor agreement on the existence of these compounds among the authors. Furthermore, no author has compared the films formed in oils containing ZDP with the films formed in non-ZDP oils.

It is seen that there are very diverse opinions on the chemical reactions that take place on sliding surfaces. From descriptions of the experimental and analytical methods used by previous investigators and from the work described in Part 1 [11], it appears that the differences of opinion arise from the following:

(1) the previous investigators used several different methods to clean theit specimens before examination;

(2) the sliding specimens used by previous investigators were taken from a wide range of geometries and test procedures;

(3) the chemical constituents in the oils were not all the same.

Further, few papers provided an adequate description of the analytical methods used, and several papers were written without the benefit of modern analytical instruments.

In this work the near latest types of instruments were used, but of more significance, the specimens were not rigorously cleaned. A part of the work consisted in determining what cleanning methods to use to remove only the liquid phases from the sliding surfaces, leaving all or most of the substances that infuence tribological properties.

In this study, the films which formed in minerals oils in the presence and in the absence of ZDP are compared. The effect of the different ZDP concentrations on the film compositions were also investigated. Film growth was monitored using Mueller 
matrix ellipsometry during the sliding experiments. Quantitative analyses of the films were done at various points in the experiment using ESCA. Elastic recoil detection (ERD) [12] was used to detect hydrogen. Fourier transform IR (FTIR) spectroscopy was used to identify organic compounds in the films. The physical and mechanical properties, the dynamics of boundary film formation and their practical implementations in tribology are discussed in a separate paper.

\section{Specimens}

The characterization of specimens and the specimen preparation procedures were described earlier in Part I [11]. In order to determine the boundary film compositions, five specimens were sectioned after films were formed in the friction tests and subjected to ESCA and ERD analysis. The identifications of the specimens are reproduced in Table 1 for convenience. The first two numbers of the specimen notation indicate the Rockwell $\mathrm{C}$ hardness of the disk specimens. The letters following the dash identify the lubricant type: $M$ stands for paraffin oil, $B$ is for base oil and $Z$ following a number indicates the percentage of ZDP in the oil. For example, specimen $53-\mathrm{M} 2 \mathrm{Z}$ specimen is a $53 \mathrm{HRC}$ disk specimen slid in paraffin oil containing $2 \% \mathrm{ZDP}$. The progression of film formation on the steel disks was monitored by an automated Mueller matrix ellipsometer. Several specimens other than the five were analyzed for the formation of organic compounds using FTIR.

The hardnesses of the disk specimens used in ESCA and ERD analysis were 47, 53,54 and 55 HRC. The initial surface roughness of the cylinder specimens was $0.02-0.025 \mu \mathrm{m} R_{\mathrm{a}}$ and of the disk specimens was 0.01 to $0.02 \mu \mathrm{m} R_{\mathrm{a}}$. The sliding speed was $0.06 \mathrm{~m} \mathrm{~s}^{-1}$. The loading procedure was by step loading in increments of $62.5 \mathrm{~N}$ every $10 \mathrm{~min}$. Two kinds of bulk oil were used as lubricants: white paraffin oil made by Mallinckrodt Company (LOT $6358 \mathrm{KCHB}$ ) and base cngine oil supplied from National Institute of Standarts and Technology (NIST). The paraffin oil consisted of only straight saturated hydrocarbons whereas the base oil included $32.5 \%$ aromatics. $1 \%$ and $2 \%$ ZDP were also added in base oil and paraffin oil respectively in some of the sliding experiments. ZDP was also supplied from NIST.

Since iron and iron oxides were extensively studied with ESCA and the peak positions were identified quite clearly, standard iron and iron oxide specimens were not prepared, instead the existing information [13-17] was used for the identification of iron and iron oxides.

TABLE 1

ESCA and ERD specimens

\begin{tabular}{lcccc}
\hline Specimen & $\begin{array}{l}\text { Maximum } \\
\text { load }(\mathrm{N})\end{array}$ & $\begin{array}{l}\text { Sliding } \\
\text { distance }\end{array}$ & $\begin{array}{l}\text { Final film } \\
\text { thickness } \\
(\AA)\end{array}$ & $\begin{array}{l}\text { Refractive } \\
\text { index of } \\
\text { film }\end{array}$ \\
\hline $54-\mathrm{M}$ & 589 & 756 & 93 & 3.20 \\
$54-\mathrm{B}$ & 713 & 432 & 82 & 3.84 \\
$47-\mathrm{M} 2 Z$ & 1890 & 1008 & 124 & 3.80 \\
$53-\mathrm{M} 2 Z$ & 1890 & 1008 & 86 & 2.52 \\
$55-\mathrm{B} 1 Z$ & 527 & 684 & 107 & 3.14 \\
\hline
\end{tabular}




\section{Spectroscopic procedures}

A PHI 5400 electron spectrometer was used with $\mathrm{Mg} \mathrm{K} \alpha$ exciting radiation $(h \nu(\mathrm{X}$ ray) $=1253.6 \mathrm{eV}$ ) at a constant power of $300 \mathrm{~W}$. The energy resolution of the high resolution spectra was $0.1 \mathrm{eV}$ with a nominal reproducibility of $\pm 0.1 \mathrm{eV}$. The pressure during ESCA analysis was typically $1 \times 10^{-8}$ Torr. The calibration of the spectrometer was such that the $\mathrm{Au} 4 \mathrm{f}_{7 / 2}$ line appeared at $83.75 \mathrm{eV}$ and the $\mathrm{Cu} 2 \mathrm{p}_{3 / 2}$ line appeared at $932.2 \mathrm{eV}$. The adventitious carbon on steel specimens consistently appeared at 284.6 $\mathrm{eV}$ binding energy for the $1 \mathrm{~s}$ line. For the depth profiles the $2 \mathrm{p}_{3 / 2}$ line of iron with a binding energy of $706.4 \mathrm{eV}$ was used as an internal reference. Ion bombardment of sample surfaces was carried out with an argon ion gun. Argon ions of $3 \mathrm{keV}$ were used with $8.5 \mu \mathrm{A}$ current intensity and $1 \mathrm{~mm}$ beam diameter. Ion etching was done at a glancing angle of $45^{\circ}$. To compensate for possible surface charging effects, a neutralizer was turned on with $0.9 \mathrm{eV}$ electron energy. Surface charging did not occur, as seen by the invariance of the pure iron $2 \mathrm{p}_{3 / 2}$ binding energy $(706.4 \pm 0.1 \mathrm{eV})$ as well as the reproducibility of sample binding energies to better than $\pm 0.2 \mathrm{eV}$ for all the independently prepared specimens.

ERD is a method for obtaining depth profiles of light elements such as hydrogen in solids. In this technique, helium ions of a few megaelectronvolts are scattered off the target but instead of measuring the energy of the scattered helium particles, the energy of the forward scattered hydrogen is measured. This is accomplished by shielding the detector from helium ions with a thin foil so that only hydrogen or deuterium ions reach the detector. The Tandetron accelerator, made by General Ionex was used with the duoplasmatron source which produced $\mathrm{He}^{+}$ions with $2.4 \mathrm{MeV}$ beam energy and $60 \mu \mathrm{C}$ beam charge. The ion beam was $3 \mathrm{~mm}$ in diameter and was directed at a glancing angle of $12.5^{\circ}$ from the specimen surface. The detector was positioned at $25^{\circ}$. Calibration of the measurements was done with $13 \mu \mathrm{m}$ thick mylar $\left(\mathrm{C}_{10} \mathrm{H}_{8} \mathrm{O}_{4}\right)$ foil.

The FTIR instruments were a Digilab FTS-20C with software IMX, and a Mattson CYGNUS 100 connected to Mattson STARLAB 020 laboratory computer. The IR window was $\mathrm{CaF}$ with a pathlength of $0.5 \mathrm{~mm}$.

\section{Electron spectroscopy for chemical analysis}

Depth profiling was done on the $53-\mathrm{M} 2 \mathrm{Z}$ and $55-\mathrm{B} 1 \mathrm{Z}$ specimens. On $54-\mathrm{B}$, two profiles were taken, one after $0.3 \mathrm{~min}$ and the other after $1.6 \mathrm{~min}$ ion etching. On $54-\mathrm{M}$ one profile was taken after $0.5 \mathrm{~min}$ ion etching and, on $47-\mathrm{M} 2 \mathrm{Z}$ one profile was taken after $0.3 \mathrm{~min}$ ion etching. $0.5 \mathrm{~min}$ etching corresponds roughly to the removal of a $20-30 \AA$ thick layer from the film surface. Figure 1 shows the survey profiles on two specimens after the first ion millings.

After running a survey profile on each specimen, the regions for high resolution scan were selected, and multiplex profiles with $0.1 \mathrm{eV}$ resolution were taken. Multiplex depth profiles of $\mathrm{Fe} 2 \mathrm{p}$ and $\mathrm{O}$ 1s regions taken on the 53-M2Z specimen are shown in Fig, 2.

Atomic concentrations of the most important elements except hydrogen are given in Table 2 for various amounts of ion etching. The sputter yield of carbon is one third that of the other elements present in the film compositions. This was considered when calculating the relative atomic concentration of carbon as described in ref. 18 . The compositional change by sputtering for other elements is smaller than for carbon 


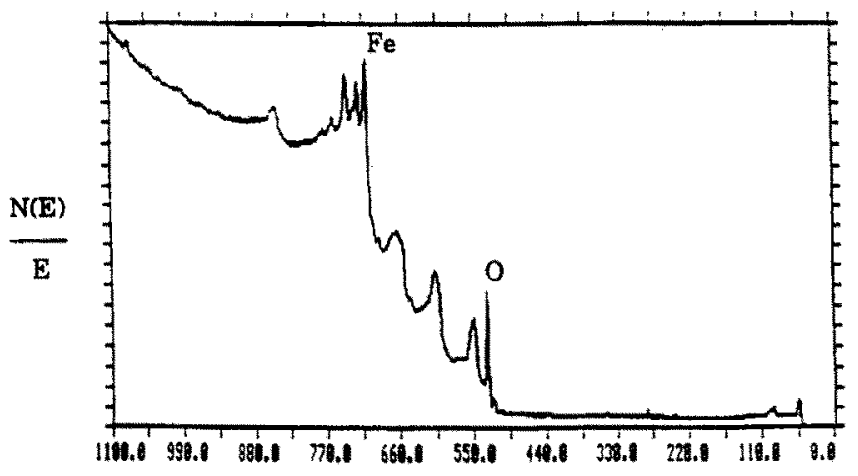

(a)

Binding Energy (eV)

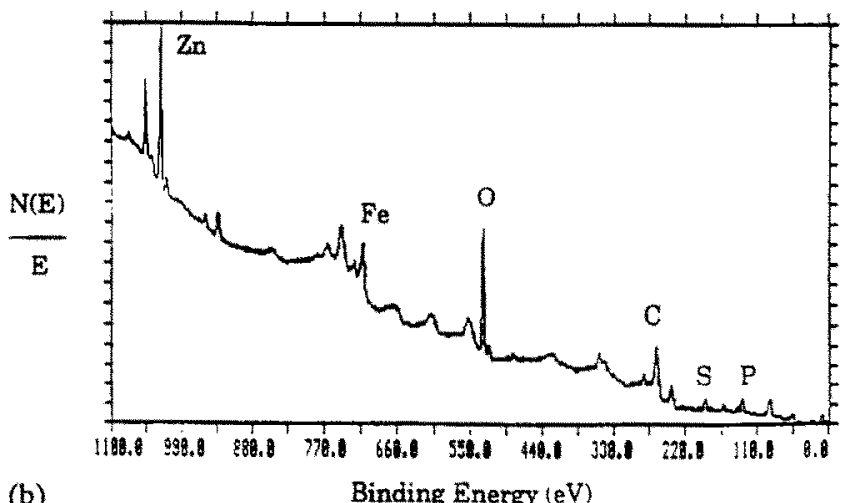

(b)

Binding Energy (eV)

Fig. 1. ESCA survey profiles on (a) specimen 54-B and (b) specimen 47-M2Z.

but the differences between the changes for individual elements in a mixture has not been resolved. The atomic concentration plots of $53-\mathrm{M} 2 \mathrm{Z}$ and $55-\mathrm{B} 1 \mathrm{Z}$ specimens are given in Figs. 3(a) and 3(b) respectively.

All films contain considerable amounts of iron, oxygen and carbon. Additionally, ZDP films contain sulfur, phosphorus and zinc, each constituting $4 \%-5 \%$ of the film compositions. Non-ZDP films contain only a trace amount of sulfur and phosphorus if any at all. The concentrations of all the elements except iron decrease along the thickness of the films almost at the same rate.

McIntyre and Zetaruk [15] investigated the effects of ion bombardment on the chemical integrity of the various iron oxide species. They found a tendency towards conversion to ferrous oxide ( $\mathrm{FeO}$ ) from the ferric oxides, i.e. $\mathrm{Fe}_{2} \mathrm{O}_{3}$ and $\mathrm{Fe}_{3} \mathrm{O}_{4}$. However, ion bombardment of iron oxides caused no reduction of oxide to metal. Thus, an oxide phase can be differentiated from iron metal by ESCA following sputtering, even though its specific chemical structure cannot be readily identified.

\subsection{Iron $2 p$ region}

High resolution spectra of the iron region revealed a complex iron peak showing a shift in binding energy due to the chemical bonding. This peak had two major contributors: elemental iron with a binding energy of $706.4 \mathrm{eV}$, and iron in compound form with a binding energy of $709.5 \pm 0.5 \mathrm{eV}$. A $98 \%$ pure iron peak was obtained 

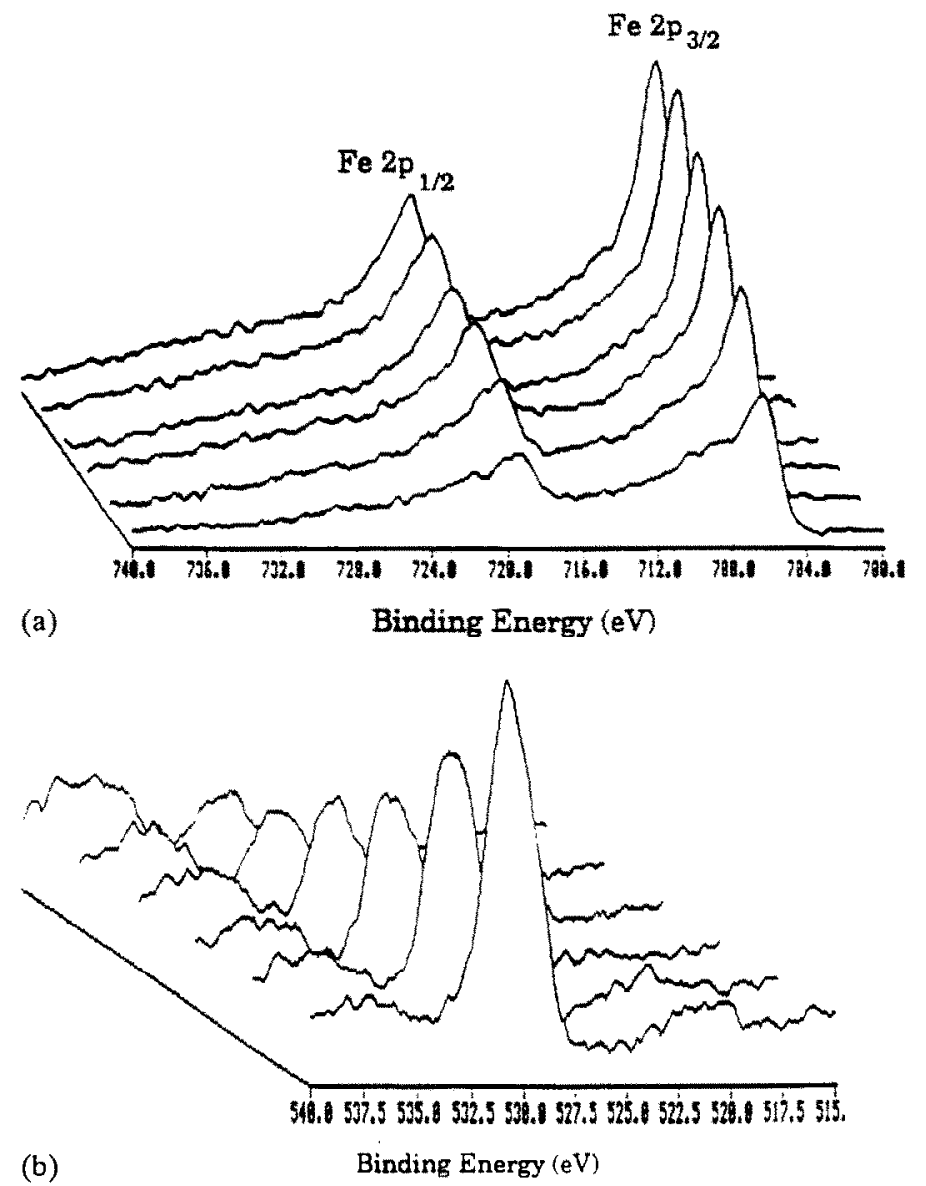

Fig. 2. ESCA depth profiles in (a) the iron $2 p$ region on specimen 53-M2Z, and (b) the oxygen 1s region on specimen 53-M2Z.

at the end of the depth profiling on specimen $53-\mathrm{M} 2 \mathrm{Z}$. The contributions of elemental iron and compound iron are determined after subtracting the normalized pure irnn peak from the complex iron peak with $\pm 5 \%$ accuracy in all cases.

An example of the separation of pure iron from a complex iron peak by the difference technique is shown in Fig. 4. Curves $a$ and $b$ show the complex iron and pure iron peaks respectively, after X-ray satellite subraction and 11-point smoothing. Curve $c$ shows both curves after three-point normalization of the pure iron peak to the complex iron peak. Curve d shows the difference between the two curves which corresponds to compound iron. The area under the compound iron peak is calculated and compared with the area under the complex iron peak (which is the sum of the purc and compound iron contributions) to find the amount of iron in compound form. The above outlined procedure was applied to every data curve and the results are tabulated in Table 3, showing the atomic percentages of pure iron and compound iron in the films. The amount of compound iron decreases and the amount of pure iron increases along the thickness of the film. 
TABLE 2

Atomic concentrations of elements in the films

\begin{tabular}{|c|c|c|c|c|c|c|c|c|c|}
\hline Specimen & $\begin{array}{l}\text { Number of } \\
\text { etchings }\end{array}$ & $\begin{array}{l}\text { Total ion } \\
\text { etching } \\
\text { time (min) }\end{array}$ & $\begin{array}{l}\text { Depth } \\
\text { (approximate) } \\
(\AA)\end{array}$ & $\begin{array}{l}\mathrm{Fe} \\
2 \mathrm{p} \\
2.957\end{array}$ & $\begin{array}{l}0 \\
1 \mathrm{~s} \\
0.711\end{array}$ & $\begin{array}{l}\text { C } \\
1 \mathrm{~s} \\
0.296\end{array}$ & $\begin{array}{l}S \\
2 p \\
0.666\end{array}$ & $\begin{array}{l}P \\
2 p \\
0.486\end{array}$ & $\begin{array}{l}\mathrm{Zn} \\
2 \mathrm{p} 3 / 2 \\
5.321\end{array}$ \\
\hline $54-\mathrm{M}$ & 1 & 0.5 & $20-30$ & 51.5 & 34 & 13 & 1 & 0.5 & \\
\hline \multirow[t]{2}{*}{ 54-B } & 1 & 0.3 & $15-20$ & 27 & 56.5 & 16.5 & & & \\
\hline & 2 & 1.6 & $60-90$ & 61.5 & 34 & 4.5 & & & \\
\hline $47 \cdot M 2 Z$ & 1 & 0.3 & $15-20$ & 10 & 47 & 18.5 & 4.5 & 11.5 & 8.5 \\
\hline \multirow[t]{6}{*}{ 53-M2Z } & 1 & 0.5 & $20-30$ & 56.5 & 22.5 & 8 & 5 & 3.5 & 4.5 \\
\hline & 2 & 1 & $40-60$ & 72.5 & 15.5 & 3.5 & 2.5 & 3.5 & 2.5 \\
\hline & 3 & 1.5 & $60-80$ & 79.5 & 12 & 3 & 2 & 2 & 1.5 \\
\hline & 4 & 2 & $80-100$ & 85 & 9 & 2 & 1.5 & 1 & 1.5 \\
\hline & 5 & 2.5 & $100-120$ & 90.5 & 5 & 2 & 1 & 0.5 & 1 \\
\hline & 6 & & $120-140$ & 92.5 & 3.5 & 2 & 1 & 0.5 & 0.5 \\
\hline \multirow[t]{5}{*}{ 55-B1Z } & 1 & 0.15 & $10-15$ & 21.5 & 41 & 23 & 5 & 6.5 & 3 \\
\hline & 2 & 0.4 & $20-30$ & 38.5 & 38 & 9.5 & 5 & 5 & 4 \\
\hline & 3 & 1.1 & $45-60$ & 54.5 & 27.5 & 7 & 4 & 3.5 & 3.5 \\
\hline & 4 & 1.8 & $65-95$ & 67.5 & 19.5 & 5 & 3 & 2.5 & 2.5 \\
\hline & 5 & 2.5 & $100-120$ & 74.5 & 15 & 5 & 2 & 1.5 & 2 \\
\hline
\end{tabular}

\subsection{Oxygen Is region}

Two oxygen peak positions were identified by comparing the oxygen 1s region of the specimens tested in oils with and without ZDP. On specimens slid in oils without $\mathrm{ZDP}$, the $529.6 \mathrm{eV}$ peak dominates and in oils with ZDP, the $530.9 \mathrm{eV}$ peak dominates as shown in Figs. 5(a) and (b) respectively. The contribution of each peak was determined for every data point by curve fitting. It is seen from Fig. 5 that the full width at half maximum (FWHM), which is the characteristic of the peaks, did not change with the changing intensity for curves 1 and 2 .

The low binding energy of $529.6 \mathrm{eV}$ is the characteristic location for oxide oxygen. The $530.9 \mathrm{eV}$ peak position must therefore correspond to an organic compound. The existence of large amounts of carbon (via ESCA) and hydrogen (via ERD) in the films and the detection of organic compounds with FTIR analysis suggests that oxygen is bonded to these elements to form an organic compound. Table 3 shows the atomic percentages of the oxide oxygen and the organic oxygen in the film compositions.

\subsection{Iron oxide analysis}

Table 3 shows that in the films formed in oils without ZDP most of the oxygen is in oxide form. Also, the iron region clearly shows that the percentage of metallic oxide is considerably higher than that in the films formed in oils with ZDP. The total amount of iron oxide in the films was calculated as follows. In order to find the amount of iron compound which is iron oxide, we look at the amount of oxygen which is in oxide form (in a previous work [2] iron oxide was identified as $\mathrm{Fe}_{3} \mathrm{O}_{4}$ ). The amount of oxide-oxygen is then multiplied by 0.75 to find the amount of iron which is in oxide form. The sum of oxide-oxygen and oxide-iron gives the percentage of total iron oxide. The remainder of the film, apart from pure iron and iron oxide is probably an organoiron compound. The film compositions are given in Table 4. While the nonZDP films (the films formed in oils without ZDP) contain $35 \%-50 \%$ oxide, ZDP films 


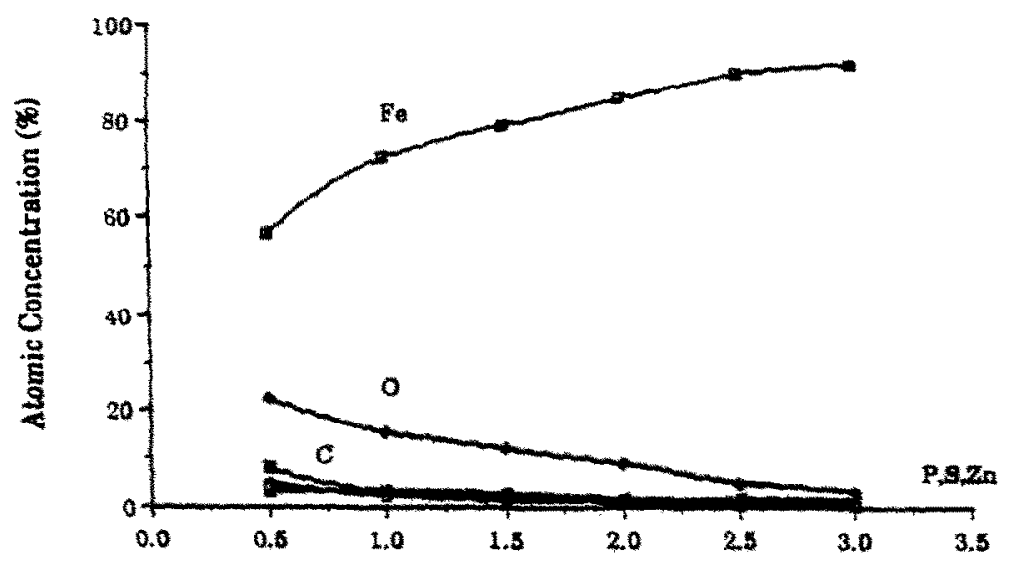

(a)

Sputtering Time (min)

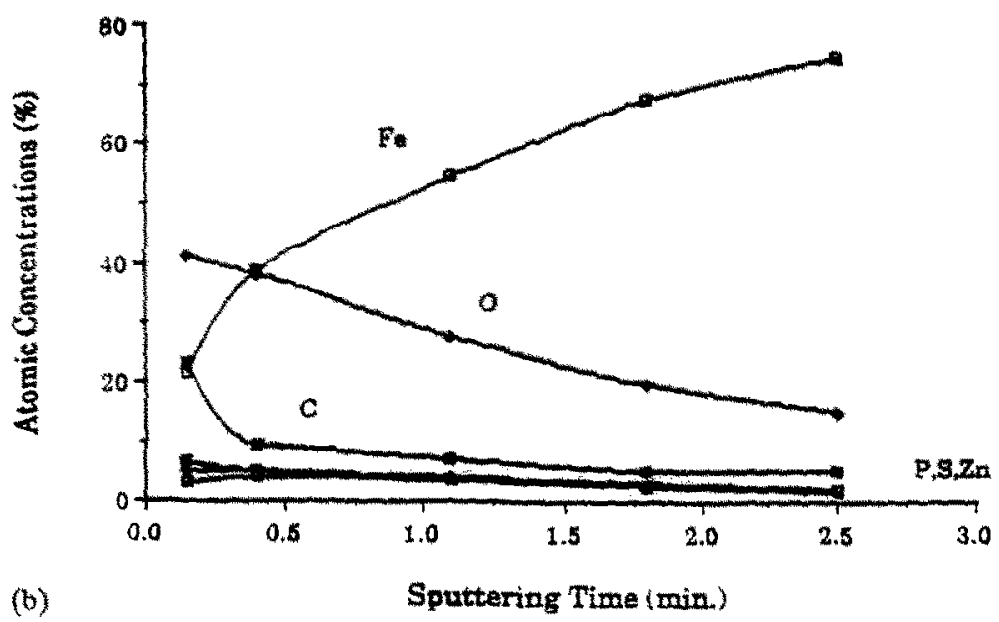

Fig. 3. Atomic concentration piot of the boundary film formed on (a) specimen 53-M2Z and (b) specimen $55-B 1 Z$ (note that hydrogen is not shown).

contain $9 \%-16 \%$ oxide. Clearly, ZDP has prevented the formation of iron oxide. In ZDP films the percentage of iron which is in compound form is higher than the percentage of iron oxide. This suggests that only a fraction of the iron compound is in the form of oxide. Comparison of the oxygen regions of the 53-M2Z and $55-\mathrm{B} 1 \mathrm{Z}$ specimens, which have $2 \%$ and $1 \%$ ZDP in the bulk oil respectively, shows that less iron oxide forms in the higher ZDP concentration. For the case of $2 \% \mathrm{ZDP}$, the amount of iron oxide was $9 \%$ of the film composition whereas in the case of $1 \%$ ZDP, the amount of oxide was $16 \%$.

The ratio of oxide oxygen to organic oxygen is increased in both ZDP and nonZDP films along the thickness from top to bottom. This indicates that an organoiron compound lies above the iron oxide layer. 

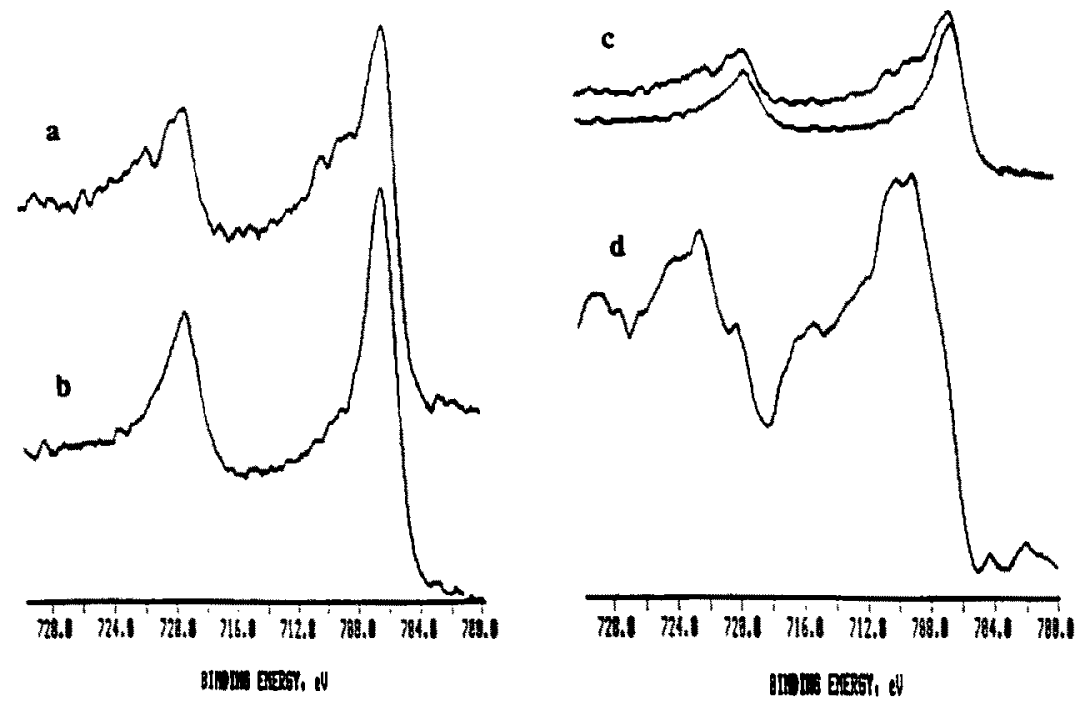

Fig. 4. Separation of pure iron contribution from the complex iron peak on specimen 53-M2Z; curve $a$, complex iron peak; curve $b$, pure iron peak; curves $c$, curve $b$ normalized and plotted with curve a prior to differencing; curve d, difference of curve a and curve b, i.e. compound iron.

\section{TABLE 3}

Separation of compound iron from elemental iron by the difference technique and separation of oxide oxygen from organic oxygen by curve fitting, results are given as percentages of the iron and oxygen peaks

\begin{tabular}{llllllll}
\hline Specimen & $\begin{array}{l}\text { Number } \\
\text { of } \\
\text { etchings }\end{array}$ & $\begin{array}{l}\text { Total ion } \\
\text { etching } \\
\text { time }(\min )\end{array}$ & $\begin{array}{l}\text { Depth } \\
\left(\begin{array}{l}\text { approximate) } \\
(\AA)\end{array}\right.\end{array}$ & $\begin{array}{l}\text { Pure } \\
\text { iron }(\%)\end{array}$ & $\begin{array}{l}\text { Compound } \\
\text { iron }(\%)\end{array}$ & $\begin{array}{l}\text { Oxide } \\
\text { oxygen }(\%)\end{array}$ & $\begin{array}{l}\text { Organic } \\
\text { oxygen }(\%)\end{array}$ \\
\hline $54-\mathrm{M}$ & 1 & 0.5 & $20-30$ & 55 & 45 & 55 & 45 \\
$54-\mathrm{B}$ & 1 & 0.3 & $15-20$ & 0 & 100 & 48 & 52 \\
& 2 & 1.6 & $60-90$ & 60 & 40 & 76 & 24 \\
$47-\mathrm{M} 2 Z$ & 1 & 0.3 & $15-20$ & 0 & 100 & 0 & 100 \\
$53-\mathrm{M} 2 Z$ & 1 & 0.5 & $20-30$ & 68 & 32 & 20 & 80 \\
& 2 & 1 & $40-60$ & 78 & 22 & 29 & 71 \\
& 3 & 1.5 & $60-80$ & 85 & 15 & 34 & 66 \\
& 4 & 2 & $80-100$ & 94 & 6 & 38 & 62 \\
& 5 & 2.5 & $100-120$ & 97 & 3 & 38 & 62 \\
$55-\mathrm{B} 1 \mathrm{Z}$ & 6 & 3 & $120-140$ & 98 & 2 & 52 & 48 \\
& 1 & 0.15 & $10-15$ & 5 & 95 & 16 & 84 \\
& 2 & 0.4 & $20-30$ & 25 & 75 & 21 & 79 \\
& 3 & 1.1 & $45-60$ & 63 & 37 & 27 & 73 \\
& 4 & 1.8 & $65-95$ & 77 & 23 & 30 & 70 \\
& 5 & 2.5 & $100-120$ & 86 & 14 & 40 & 60 \\
\hline
\end{tabular}

4.4. Shake-up satellite of iron $2 p_{3 / 2}$ line

For the specimens which were run in oils with $Z D P$, the $2 \mathrm{p}_{3 / 2}$ line of iron compounds was positioned at $709.5 \pm 0.5 \mathrm{eV}$, having a FWHM of about $3.7 \mathrm{eV}$. The peaks had 
(a)

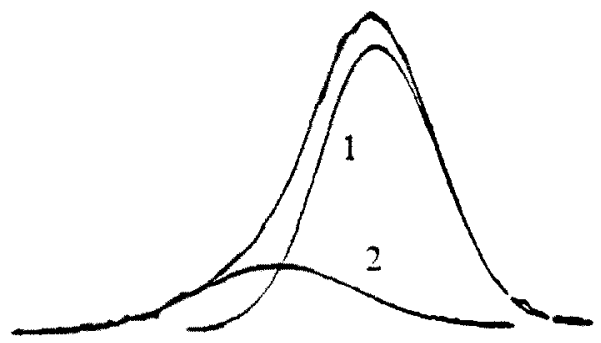

(b)

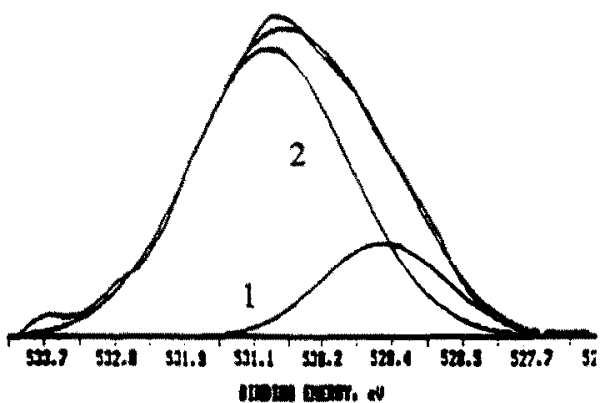

Fig. 5. Oxygen regions: (a) 54-B (plain base oil), $529.6 \mathrm{eV}$ peak dominates; (b) 53-M2Z2 (mineral oil plus $2 \% \mathrm{ZDP}$ ), $530.9 \mathrm{eV}$ peak dominates.

\begin{tabular}{lcccc}
\hline & $54-\mathrm{B}$ & \multicolumn{3}{c}{$53-\mathrm{M} 2 Z 2$} \\
\hline Curve & 1 & 2 & 1 & 2 \\
Peak position & 1 & 530.9 & 529.6 & 530.9 \\
FWHM (eV) & 529.6 & 2.3 & 1.8 & 2.3 \\
Percentage of total area & 1.7 & 24 & 20 & 80 \\
\hline
\end{tabular}

a strong shake-up satellite. Satellite intensity is defined as [11]:

$I_{\text {sat }}=A_{\text {sat }} /\left(A_{\text {sat }}+A_{\text {primary }}\right)$

where $A_{\text {sat }}$ and $A_{\text {primary }}$ are areas under the satellite and primary peaks respectively. Figure 6 shows two examples of the determination of the satellite intensity by curve fitting on two different specimens. Figure 6(a) applies to the $47-\mathrm{M} 2 Z$ specimen and was obtained after $0.3 \mathrm{~min}$ ion milling. As we see from Table 3 , the iron peak has zero contribution from the elemental iron. Figure 6(b) applies to the 55-B1Z2 specimen in which case $25 \%$ of the iron peak was elemental iron. The difference technique was applied to remove the elemental iron. In both cases, the satellite intensities were about 0.4 . The satellite peak positions were separated by $3.8-4.2 \mathrm{eV}$ from the primary $2 \mathrm{p}_{3 / 2}$ peak. The separation between the $2 \mathrm{p}_{3 / 2}$ and $2 \mathrm{p}_{1 / 2}$ lines was $13.7 \mathrm{eV}$. The close resemblance of Figures $6(\mathrm{a})$ and (b) also indicates the success of the difference technique. For the non-ZDP specimens, the satellite intensities were moderate: 0.2 and separated from the primary $2 \mathrm{p}_{3 / 2}$ peak by $5-5.5 \mathrm{eV}$.

According to Brant and Feltham [16], paramagnetic (high spin) iron compounds have large FWHM (3-5 eV) and diamagnetic (low spin) iron compounds have small FWHM (1-2 eV). Also, the satellite intensities of the paramagnetic iron compounds are strong $(0.2-0.6)$ compared with diamagnetic iron compounds (less than 0.2 ). 
TABLE 4

Film compositions determined from Tables 2 and 3

\begin{tabular}{lllllll}
\hline Specimen & $\begin{array}{l}\text { Number of } \\
\text { etchings }\end{array}$ & $\begin{array}{l}\text { Ion etching } \\
\text { time (min) }\end{array}$ & $\begin{array}{l}\text { Depth } \\
\text { (approximate) } \\
(\AA)\end{array}$ & $\begin{array}{l}\text { Pure } \\
\text { iron }(\%)\end{array}$ & $\begin{array}{l}\text { Iron } \\
\text { oxide }(\%)\end{array}$ & $\begin{array}{l}\text { Organoiron } \\
\text { compound (\%) }\end{array}$ \\
\hline $54-\mathrm{M}$ & 1 & 0.5 & $20-30$ & 28 & 33 & 39 \\
$54-\mathrm{B}$ & 1 & 0.3 & $15-20$ & 0 & 48 & 52 \\
& 2 & 1.6 & $60-90$ & 37 & 46 & 17 \\
$47-\mathrm{M} 2 Z$ & 1 & 0.3 & $15-20$ & 0 & 0 & 100 \\
$53-\mathrm{M} 2 Z$ & 1 & 0.5 & $20-30$ & 39 & 8 & 53 \\
& 2 & 1 & $40-60$ & 56 & 8 & 36 \\
& 3 & 1.5 & $60-80$ & 67 & 7 & 26 \\
& 4 & 2 & $80-00$ & 80 & 6 & 14 \\
& 5 & 2.5 & $100-120$ & 88 & 4 & 8 \\
$55-\mathrm{B} 1 \mathrm{Z}$ & 6 & 3 & $120-140$ & 91 & 3 & 6 \\
& 1 & 0.15 & $10-15$ & 1 & 12 & 87 \\
& 2 & 0.4 & $20-30$ & 10 & 14 & 76 \\
& 3 & 1.1 & $45-60$ & 35 & 16 & 49 \\
& 4 & 1.8 & $65-95$ & 52 & 10 & 38 \\
\hline
\end{tabular}

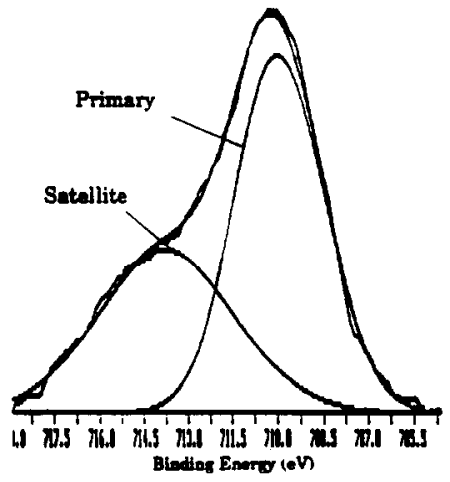

(a)

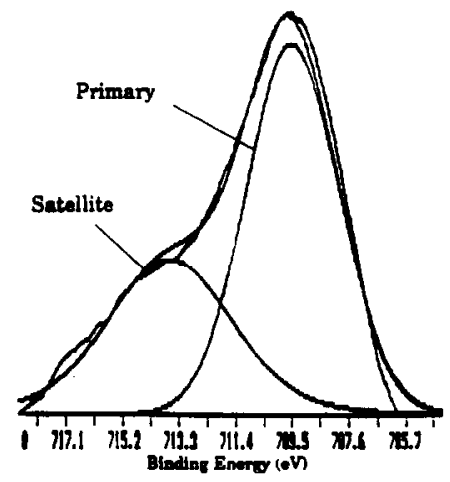

(b)

Fig. 6. Determination of the compound iron satellite intensity: (a) 47-M2Z, the original data; (b) 55-B1Z, after subtracting the elemental iron contribution.

\begin{tabular}{lcccc}
\hline & $47-\mathrm{M} 2 \mathrm{Z}$ & & $55-\mathrm{B} 1 \mathrm{Z}$ & \\
\hline Curve & Primary & Satellite & Primary & Satellite \\
peak position $(\mathrm{eV})$ & 709.8 & 713.7 & 709.5 & 713.6 \\
FWHM $(\mathrm{eV})$ & 3.5 & 5.4 & 3.7 & 5.0 \\
Percentage of total area & 41 & 59 & 38 & 62 \\
\hline
\end{tabular}


Furthermore, they observed that the separation between the $2 \mathrm{p}_{3 / 2}$ and $2 \mathrm{p}_{1 / 2}$ lines of paramagnetic and diamagnetic iron complexes are $13-13.7 \mathrm{eV}$ and $12.7 \mathrm{eV}$ respectively. The satellite position was separated by $3-5 \mathrm{eV}$ from the primary peak, with larger values for high spin and smaller values for low spin complexes.

Comparison of our data with Brant and Feltham's data shows that the iron compounds formed during our friction tests are more likely to be paramagnetics. Organoiron compounds were most probably formed by the reaction of free radicals with steel surfaces. X-ray irradiation may convert organic compounds back to free radicals which are paramagnetics $[19,20]$. This could be one of the reasons why our films showed a strong shake-up satellite in the iron region.

There may be other reasons for the strong shake-up satellite than paramagnetism. Allen et al. [17] have done XPS analyses on iron-oxygen systems. They reported that strong shake-up satellites of the iron oxide peaks are also related to the presence of an excess of oxygen atoms in the surface as well as to non-stoichiometry of the oxides. There is a considerable amount of oxygen on all of our specimens. Also the short time available (microseconds) for a complete oxidation reaction during sliding conditions may cause non-stoichiometry. Thus, paramagneticity, excess oxygen and intrinsic nonstoichiometry may all contribute to the strong shake-up satellites of primary peaks of iron compounds formed on the sliding steel surfaces.

\subsection{1s region}

Adventitious carbon $1 \mathrm{~s}$ peak was positioned at $284.6 \pm 0.1 \mathrm{eV}$ binding energy for all of the specimens. After $0.5 \mathrm{~min}$ of ion milling the peak position was still at 284.6 $\mathrm{eV}$ except for specimen 53-M2Z where it had shifted to $284.0 \mathrm{eV}$. However, for the subsequent millings the peak position gradually shifted to $283.8 \pm 0.1 \mathrm{eV}$ for all of the specimens. This shift to a lower binding energy indicates that the electron density in carbon atoms increased via chemical bonding. Obviously, iron is the best candidate for electron donation, especially with increasing depth, indicating the formation of iron carbide, either $\mathrm{FeC}$ or $\mathrm{Fe}_{3} \mathrm{C}$, near to the steel. To make sure that $0.5 \mathrm{~min}$ of ion milling is enough to eliminate all the adventitious carbon, $0.5 \mathrm{~min}$ ion milling was done on the bare steel substrate and it was seen that all the adventitious carbon was sputtered away.

\subsection{Other elements}

Non-ZDP films consist almost entirely of iron, oxygen, carbon and hydrogen, whereas ZDP films also contain sulfur, phosphorus, and zinc, totaling between $10 \%$ and $15 \%$ of the film compositions.

As we saw in the oxide analysis, the addition of 1\%-2\% ZDP in bulk oils reduces the iron oxide formation by a factor of $3-4$. We can conclude that the presence of sulfur, phosphorus and zinc in the films discourages the formation of iron oxide and iron-carbon compounds while it encourages the formation of organoiron compounds.

A sulfur 2p peak was located at $161.7 \mathrm{eV}$ having $2.5 \mathrm{eV}$ FWHM. A phosphorus $2 \mathrm{p}$ peak was located at $133.1 \pm 0.2 \mathrm{eV}$ having $2.2 \mathrm{eV}$ FWHM. The sulfur peak has a tail towards the high binding energy side. Both sulfur and phosphorus peaks show a chemical shift from their elementary position.

Therc was insufficicnt information on whether sulfides, sulfates, phosphides and phosphates of iron or zinc had formed. Sulfur, phosphorus and zinc most probably enter into the organoiron compound, thereby improving its mechanical properties.

The $2 \mathrm{p}_{3 / 2}$ line of zinc was located at $1021.9 \pm 0.1 \mathrm{eV}$. The position did not change with ion milling. 


\section{Elastic recoil detection (bydrogen) analysis}

On each of the specimens 54-M and 47-M2Z, three ERD spectra were obtained. The first spectrum was obtained right after polishing before the friction test, the second was after the friction test, off the wear track, and the third was after the friction test, on the wear track. The results are shown in Fig. 7. The heights of the peaks are proportional to the relative hydrogen content and the widths of the peaks are proportional to the depth of the hydrogen layer. Computer simulation of the curves showed that on the plain specimens hydrogen constituted $5 \%$ of the composition of the layer. After the friction test, off the wear track, the hydrogen content was $8 \%$ whereas on the wear track it was $13 \%$. Clearly, friction increases the hydrogen content considerably.

\section{FTIK analysis}

FTIR spectroscopy was used to determine the decomposition of plain oil and ZDP in oil due to sliding, and the formation of organic compounds on the disk sliding tracks. The thermal oxidation products of mineral oils include alcohols $(\mathrm{R}-\mathrm{OH})$, ketones $(\mathrm{R}-\stackrel{\mathrm{O}}{\mathrm{C}}-\mathrm{R})$, acids $(\mathrm{R}-\stackrel{\mathrm{O}}{\mathrm{C}}-\mathrm{OH})$ and esters $(\mathrm{R}-\stackrel{\mathrm{O}}{\mathrm{C}}-\mathrm{O}-\mathrm{R})$ among other oxygencarrying compounds. After oxidation of base oil on a thermal plate at $180^{\circ} \mathrm{C}$ for several hours, the $\mathrm{C}=\mathrm{O}$ absorption region of the oil sample was analyzed by FTIR to identify the end products. The deconvolution of the $\mathrm{C}=\mathrm{O}$ region, as shown in Fig. 8 , indicates the presence of ketones, acids and esters as oxidation products. The details of the degradation mechanisms will not be given here but can be found in refs. 21 and 22 which also give a comprehensive survey of the related literature.

To determine the extent of decomposition of oil due to sliding, samples of oil which originally contained $2 \%$ ZDP were collected before and after the sliding experiments and subjected to FTIR analysis. However, the oil bath shown in Fig. 1

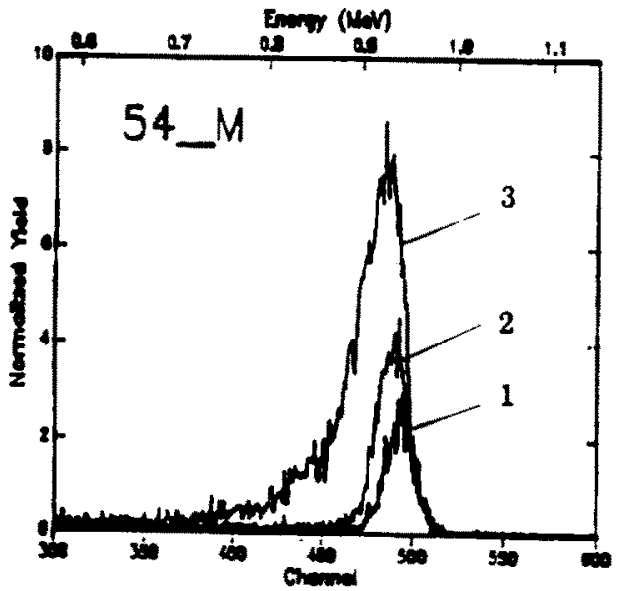

(a)

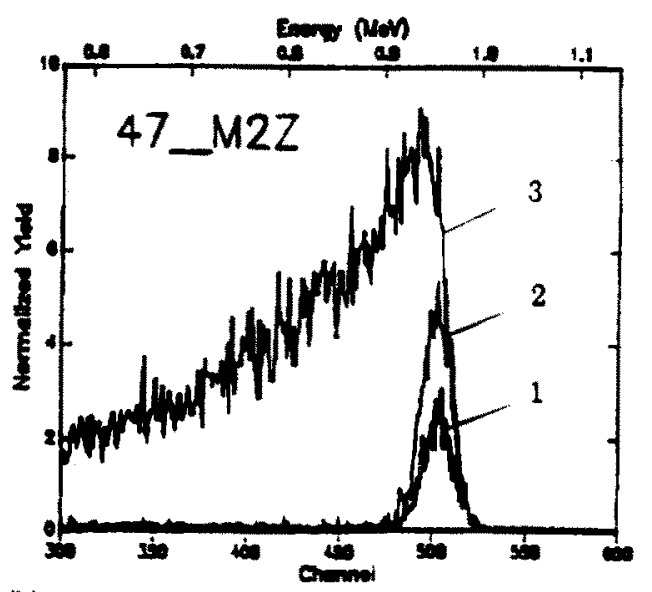

(b)

Fig. 7. Hydrogen spectra, (a) on specimen 54-M, (b) on specimen 47-M2Z: spectrum 1, before friction test; spectrum 2, after friction test, outside the wear track; spectrum 3, after friction test, on the wear track. 


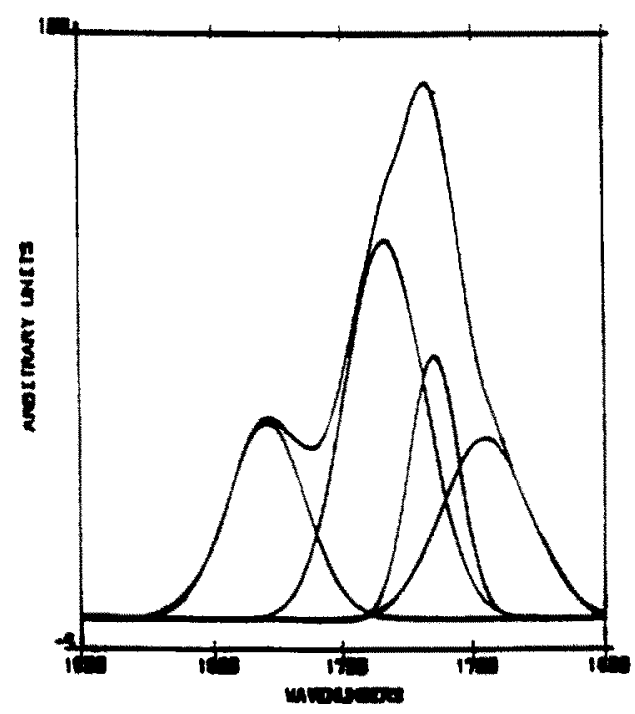

Fig. 8. Base oil oxidation products: deconvolution of $\mathrm{C}=\mathrm{O}$ region.

Peak assignments:

$1778 \mathrm{~cm}^{-1}$ alkyl diesters, vinyl esters

$1734 \mathrm{~cm}^{-1}$ alkyl aldehyde, alkyl ester
$1715 \mathrm{~cm}^{-1}$ alkyl ketone, alkyl acid $1695 \mathrm{~cm}^{-1}$ aryl ketone, aryl acid

OIl Bath

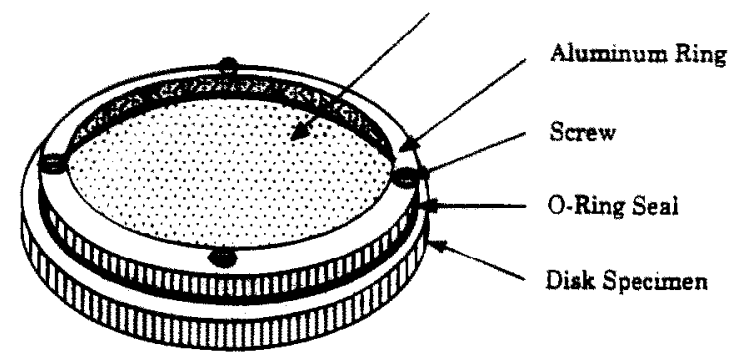

Fig. 9. Fixture for small volume oil bath.

of Part I [11] was too large $\left(200 \mathrm{~cm}^{3}\right)$ to see the degradation of oil in short time experiments. To enhance the degradation phenomena, a fixture, shown in Fig. 9, was made so that a small volume of oil $\left(5 \mathrm{~cm}^{3}\right)$ could be used. The sliding time was also increased.

A $54 \mathrm{HRC}$ disk specimen was slid against a 58 HRC cylinder under a load of $288 \mathrm{~N}$ in mineral oil plus $2 \% \mathrm{ZDP}$ for $14 \mathrm{~h}$ (54-M2Z). Oil samples were collected before and after the sliding test for FTIR analysis. The spectrum of the $P-O$ bond of ZDP, Fig. 10, shows a decrease in absorption intensity with sliding. This indicates the decomposition of ZDP due to sliding. Furthermore, the $\mathrm{C}=\mathrm{O}$ region of the same tested oil showed the presence of only cster, with no ketone or acid, Fig. 11(a). For comparison a $46 \mathrm{HRC}$ disk specimen (46-B) was slid in plain base oil (i.e. no ZDP), under a load of $320 \mathrm{~N}$ for $8 \mathrm{~h}$. The $\mathrm{C}=\mathrm{O}$ region of oil showed the presence of ester, acid and ketone, Fig. 11(b). However, in the 46-B case, the amounts of acid and ketone were greater than the amount of ester, as opposed to the 54-M2Z case. 


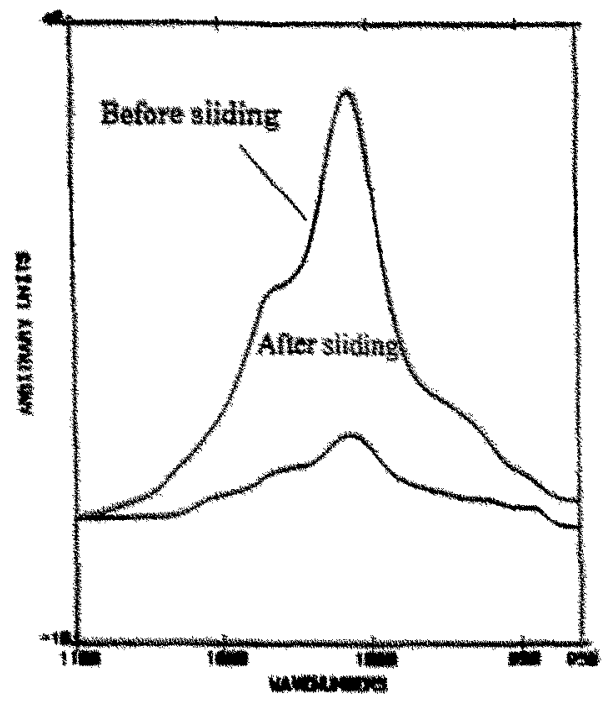

Fig. 10. Degradation of $2 \mathrm{DP}$ in mineral oll due to sliding: $\mathrm{F}$. $\mathrm{O}$ of $\mathrm{ZDP}$.

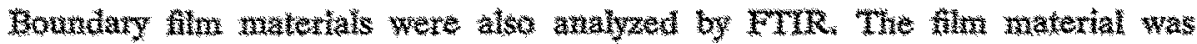
scraped from the steel surface by razor bade and diluted in a notholar solvent and analyzed. Compatison of $C=0$ regitons of the firm from $54-\mathrm{M} 2 Z$ and $46-\mathrm{B}$ specimen showed that the ratio of ester to acid and ketones was highet in $54-\mathrm{M} 22$ fims that in $46-8$ film. Apparenty the presence of $2 D P$ favors the formation of esters.

Comparison of hims formed on soter steels in olls with and without ZDP also showed that the presence of ZDP in oll fawors ester fomation, Fig. $12 . A 30$ HRC disk specimen $(30-\mathrm{M} 22)$ was slid in paraftin oil plus $2 \%$ 2DP solution under a load of $320 \mathrm{~N}$ for $6 \mathrm{~h}$. The film formed on $30 \mathrm{MM} 2 \mathrm{Z}$ showed strong ester and weak acid and ketone peaks, Fig. 12(a). A 22 HRC specimen (22 B) was slid in base on under $350 \mathrm{~N}$ for $8 \mathrm{~h}$, The Alm formed on $22-\mathrm{B}$ specimen had very little compounds containing the $\mathrm{C}=\mathrm{Q}$ group on the sufface, Fig. $12(\mathrm{~b})$.

In general, FTR w1tulysis has shown the presence of organtc compounds in the fim compositions. Combinting the FTRR and ESCA results suggests that the reactions between the iron and ketones, acids and esters result in the formation of complex organoiron compounds. Under suitable slowitug condition these organoiron compounde may undergo polynerization. For example, the presence of $Z D P$ favors the fomation of ester-based organoirons with may polymerize to diester or triester organoiton compounds as was described in ref. 2 ,

\section{Conclusions}

(1) The composition of two iron compounds was identifed. An oxygen peak tocated at 529.6 eV binding energy indicated the lomation of iron oxide, in particular $\mathrm{Fe}_{3} \mathrm{O}_{4}$ The detection a a large anount of irow, oxyzen, carton (via ESCA), bydrogen (via ERD) and organic compounds (via FTR) in the flum compositions indicated the formation of organoiron compounds as well during sliding on the steel surfaces. 


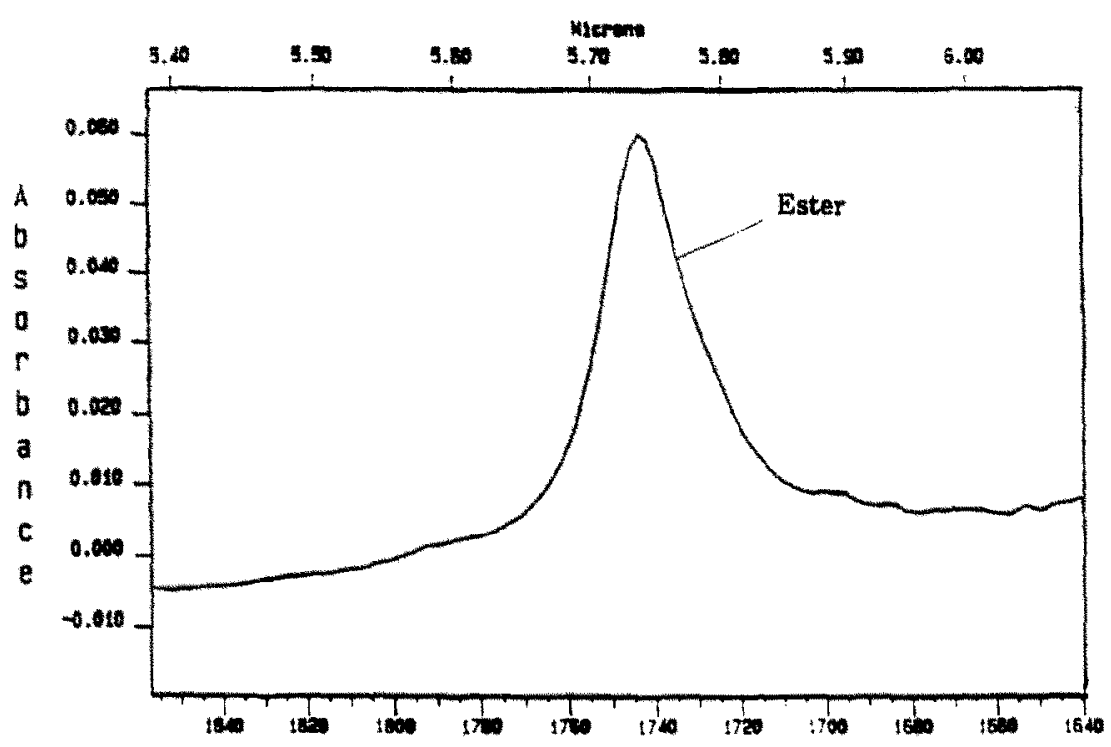

(a)

\section{Wavenumbers}

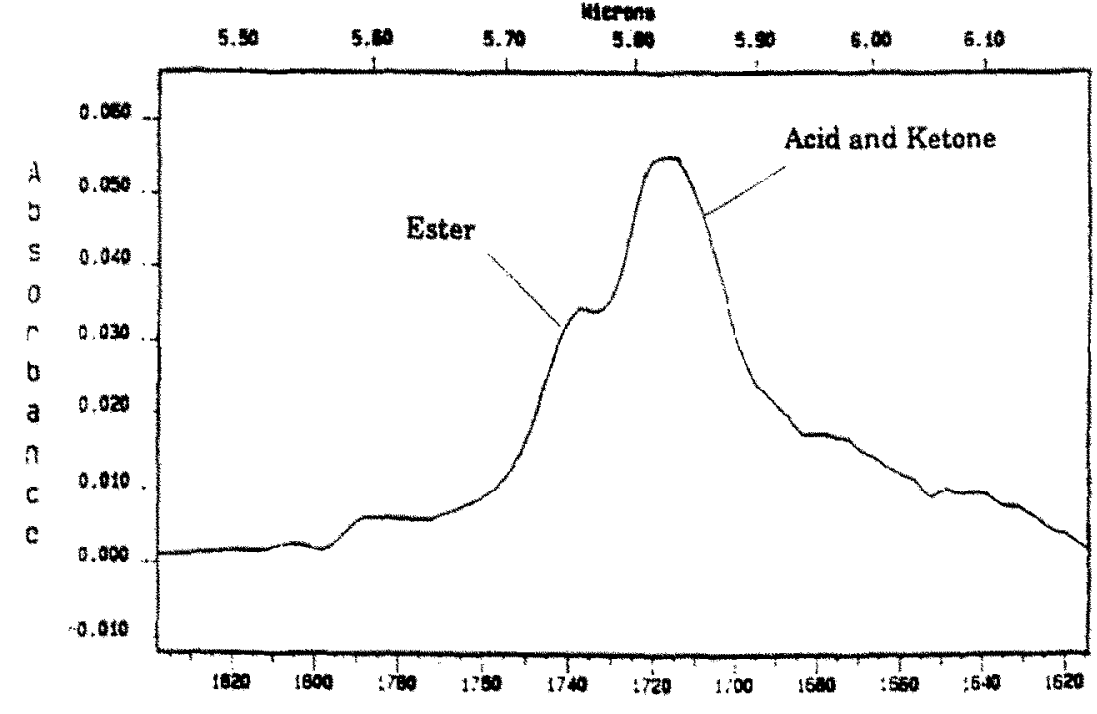

(b)

\section{Wavenumbers}

Fig. 11. $C=O$ region of the oil for (a) 54-M2Z showing ester, and (b) 46-B showing strong acid and ketone peak and weak ester peak.

(2) $2 \%$ ZDP in mineral oil lubricants reduced the iron oxide formation in the films to one third or one fourth of that produced in oils without ZDP. Chemisorption of sulfur, phosphorus and zinc on the surface encouraged the formation of organoiron compounds and also improved the mechanical properties of the organoiron compound. 


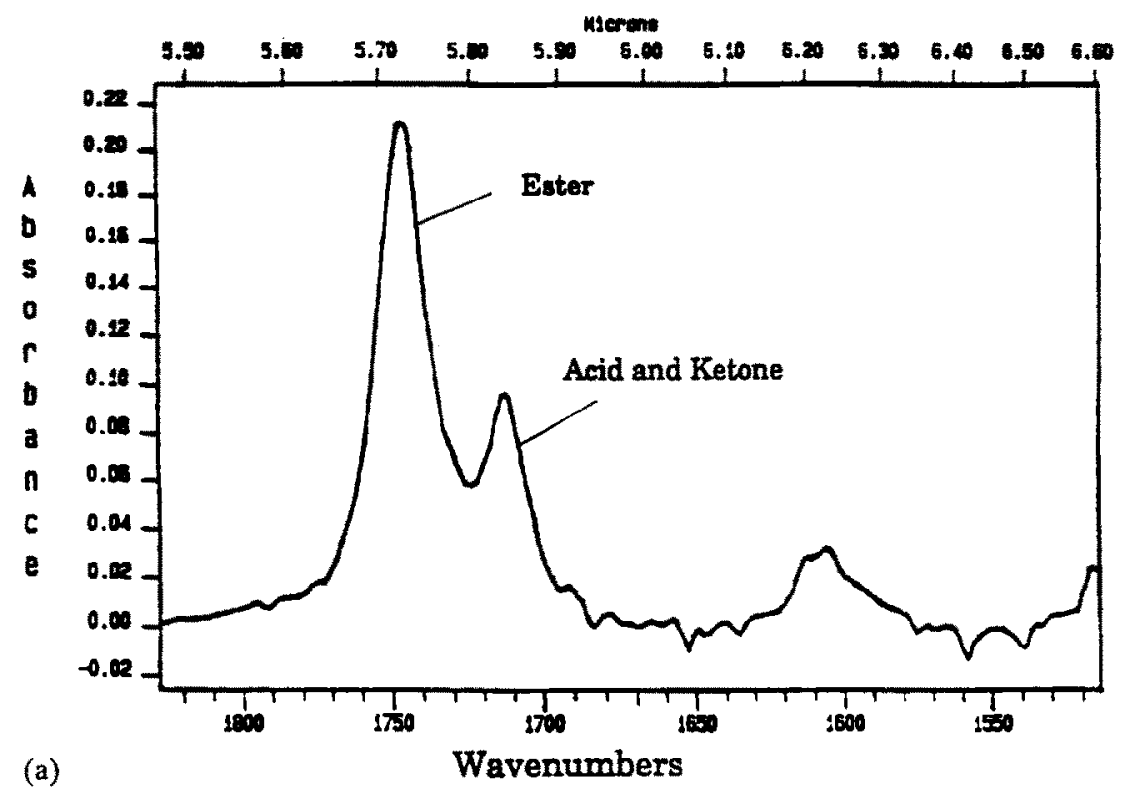

(a)

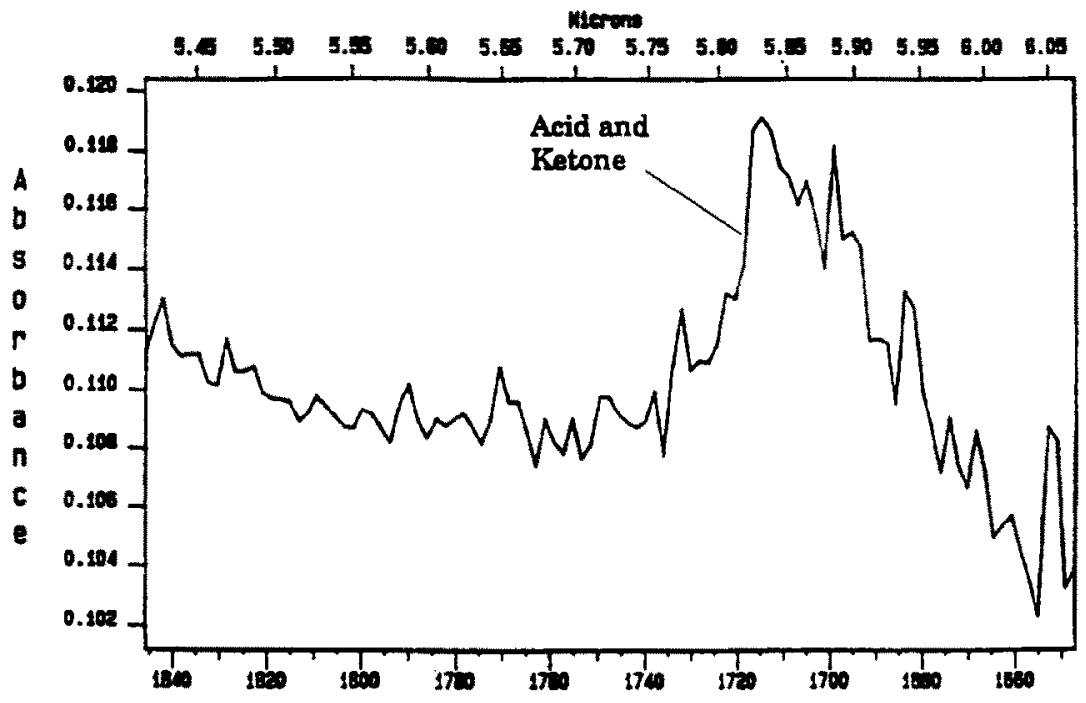

(b)

\section{Wavenumbers}

Fig. 12. $\mathrm{C}=\mathrm{O}$ region of the boundary film formed on (a) $30-\mathrm{M} 2 \mathrm{Z}$ specimen showing strong ester and weak acid and ketone peaks, and (b) 22-B specimen showing no ester and very weak acid and ketone peaks.

(3) FTIR analysis showed that in the oils with ZDP, ester-based organoiron compounds formed on the sliding steel surfaces. In the plain mineral oils, ketoneand acid-based organoiron compounds formed. When a very soft steel disk ( 22 HRC) was slid in plain mineral oil, hardly any organic compound was detected in the film.

(4) Organoiron compounds become richer in iron along the thickness. Furthermore, the ratio of iron oxide to organoiron compound increases along the thickness from 
top to bottom. At the bottom of the film next to the steel substrate a small amount of iron-carbon compound ( $\mathrm{FeC}$ or $\mathrm{Fe}_{3} \mathrm{C}$ ) forms.

(5) The strong shake-up satellite of the iron $2 \mathrm{p}_{3 / 2}$ line indicates that the iron compounds formed during sliding may be paramagnetics.

\section{Acknowledgment}

We are grateful to the National Science Foundation and in the person of Dr. J. Larsen-basse for financial support.

\section{References}

1 R. S. Fein and K. L. Kreuz, Chemistry of boundary lubrication of steel by hydrocarbons, ASLE Trans., 8 (1965) 29-38.

2 R. S. Fein and K. L. Kreuz, Lubrication and wear, Lubrication, 51 (6) (1965) 61-80.

3 R. Battino (ed.), Oxygen and Ozone, IUPAC: Solubility Data Series, Vol. 7, Pergamon, Oxford, 1981.

4 A. C. Bose, E. E. Klaus and E. J. Tewksburry, Evaluation of wear products produced by some chemical reactions in boundary lubrication, ASLE Trans., 19 (4) (1975) 287-292.

5 R. O. Bjerk, Oxygen, an extreme pressure agent, ASLE Trans., 19 (4) (1975) 287-292.

$6 \mathrm{~S}$. C. Kang and K. C. Ludema, The breaking-in of lubricated surfaces, Wear, 108 (1986) 375-384.

7 B. A. Baldwin, Chemical characterization of wear surfaces using X-ray photoelectron spectroscopy, ASLE Trans., 32 (3) (1975) 125-130.

8 R. J. Bird and D. Galvin, The application of photoelectron spectroscopy to the study of E.P. films on lubricated surfaces, Wear, 37 (1976) 143-167.

9 R. C. Watkins, The antiwear mechanism of ZDDPs, Part II, Tribology Int., 15 (1982) 13-15.

10 J. M. Martin, M. Belin, J. L. Mansot, H. Dexpert and P. LaGarde, Friction-induced amorphization with ZDDP, an EXAFS study, ASLE Trans., 29 (4) (1985) 523-531.

11 B. Çavdar and K. C. Ludema, Dynamics of dual formation in boundary lubrication of steels, part I: functional nature and mechanical properties, Wear, 148 (1991) 303.

$12 \mathrm{~A}$. Turos and O. Meyer, Depth profiling of hydrogen by detection of recoiled protons, Nucl. Instrum. Methods B, 4 (1984) 92-97.

$13 \mathrm{C}$. K. Brundle, T. J. Chuang and K. Wandelt, Core and valence level photoemission studies of iron oxide surfaces and the oxidation of iron, Surf. Sci., 68 (1977) $459-468$.

14 P. Mills and J. L. Sullivan, A study of the three core level electrons in iron and its three oxides by means of $X$-ray photoelectron spectroscopy, J. Phys. D, 16 (1983) 723-732.

15 N. S. MeIntyre and D. G. Zetaruk, X-ray photoelectron spectroscopic studies of iron oxides, Anal. Chem., 49 (11) (1977) 1528.

16 P. Brant and R. D. Feltham, X-ray photoelectron spectra of iron complexes: correlation of iron 2p satellite intensity with complex spin state. J. Electron Spectrosc., 32 (1983) 205-221.

17 G. C. Allen, M. T. Curtis, A. J. Hooper and P. M. Tucker, X-ray Photoelectron Spectroscopy of Iron-Oxygen Systems, Dalton, 1974, J. Chem. Soc. (London), pp. 1525-1530.

18 D. Briggs and M. P. Seah, Practical Surface Analysis by Auger and X-ray Photoelectron Spectroscopy, Wiley, New York, 1985, p. 214.

19 D. H. Martin, Magnetism in Solids, MIT Press, Cambridge, MA, 1967, p. 216.

20 O. H. Wheeler, Physical Organic Chemistry, Elsevier, Amsterdam, 1966, p. 135.

$21 \mathrm{~J}$. Duan, Oxidation and polymerization in bulk lubricant and lubricant-steel interface, $P h . D$. Thesis, University of Michigan, Ann Arbor, MI, 1990.

22 W. R. Jones, Thermal and oxidative stabilities of liquid lubricants, Proc. Int. Conf on Tribology in the 1980 s, 1985 , pp. $402-439$. 